\title{
Combined Use of Delamanid and Bedaquiline to Treat Multidrug-Resistant and Extensively Drug-Resistant Tuberculosis: A Systematic Review
}

\author{
Giovanni Battista Migliori ${ }^{1}$, Emanuele Pontali ${ }^{2}$, Giovanni Sotgiu ${ }^{3}$, Rosella Centis ${ }^{1}$, \\ Lia D'Ambrosio ${ }^{1,4}$, Simon Tiberi ${ }^{5}$, Marina Tadolini ${ }^{6}$ and Susanna Esposito ${ }^{7,8, *}$
}

1 World Health Organization Collaborating Centre for Tuberculosis and Lung Diseases, Maugeri Institute, IRCCS Tradate 21049, Italy; giovannibattista.migliori@icsmaugeri.it (G.B.M.);

rosella.centis@icsmaugeri.it (R.C.); liadambrosio59@gmail.com (L.D.)

Department of Infectious Diseases, Galliera Hospital, Genoa 16128, Italy; pontals@yahoo.com

3 Clinical Epidemiology and Medical Statistics Unit, Department of Biomedical Sciences, University of Sassari, Sassari 07100, Italy; gsotgiu@uniss.it

4 Public Health Consulting Group, Lugano CH-6904, Switzerland

5 Division of Infection, Royal London Hospital, Barts Health NHS Trust, 80 Newark Street, London E1 2ES, UK; simon.tiberi@bartshealth.nhs.uk

6 Unit of Infectious Diseases, Department of Medical and Surgical Sciences, Alma Mater Studiorum University of Bologna, Bologna 40138, Italy; mtadolini@hotmail.com

7 Pediatric Clinic, Department of Surgical and Biomedical Sciences, Università degli Studi di Perugia, Perugia 06129, Italy

8 Pediatric Highly Intensity Care Unit, Fondazione IRCCS Ca' Granda Ospedale Maggiore Policlinico, Milan 20122, Italy

* Correspondence: susanna.esposito@unimi.it; Tel.: +39-075-5784417; Fax: +39-075-5784415

Academic Editor: Katalin Prokai-Tatrai

Received: 30 December 2016; Accepted: 27 January 2017; Published: 7 February 2017

\begin{abstract}
The new drugs delamanid and bedaquiline are increasingly being used to treat multidrug-resistant (MDR-) and extensively drug-resistant tuberculosis (XDR-TB). The World Health Organization, based on lack of evidence, recommends their use under specific conditions and not in combination. No systematic review has yet evaluated the efficacy, safety, and tolerability of delamanid and bedaquiline used in combination. A search of peer-reviewed, scientific evidence was carried out, aimed at evaluating the efficacy/effectiveness, safety, and tolerability of delamanid and bedaquiline-containing regimens in individuals with pulmonary/extrapulmonary disease, which were bacteriologically confirmed as M/XDR-TB. We used PubMed to identify any relevant manuscripts in English up to the 23 December 2016, excluding editorials and reviews. Three out of 75 manuscripts retrieved satisfied the inclusion criteria, whilst 72 were excluded for dealing with only one drug (three studies), being recommendations (one study) or identifying need for their use (one study), focusing on drug resistance aspects (six studies) or being generic reviews/other studies (61 papers). The studies retrieved reported two XDR-TB cases observed for six months and achieving consistent sputum smear and culture conversion. Case 2 experienced a short break of bedaquiline, which was re-started after introducing verapamil. After a transient and symptom-free increase of the QT interval from week 5 to 17 , it then decreased below the $500 \mathrm{~ms}$ threshold.
\end{abstract}

Keywords: MDR-TB; XDR-TB; delamanid; bedaquiline; effectiveness; safety; tolerability 


\section{Introduction}

According to the World Health Organization (WHO), tuberculosis (TB) was responsible for over 10.4 million cases of disease in 2015, 480,000 of whom were affected by multidrug-resistant (MDR)-TB ( $10 \%$ meeting the criteria for extensively drug-resistant (XDR)-TB) and 100,000 by rifampicin-resistant TB, all contributing to an estimated 190,000 deaths [1-4].

The challenges of treating these cases are well known by clinicians operating in MDR-/XDR-TB reference centres, due to the long duration of treatment, the cost of expensive regimens, poor drug tolerability associated with frequent adverse events, and a high treatment failure rate [3-10]. As a result, as of today not all diagnosed MDR-TB cases have had access to quality treatment [1].

In 2016 the approach to design MDR-TB regimens has changed from the original stepwise approach based on five groups of drugs in priority order $[9,11]$ to a new approach based on the new drugs' classification $[7,12,13]$.

The new classification includes delamanid and bedaquiline in group D2 [7], their use is recommended under specific conditions in adults (e.g., for six months, at the recommended doses in addition to an optimised background regimen, in the presence of pharmacovigilance and informed consent, under adequate clinical and QT interval monitoring) [14-16]. Delamanid use was recently approved for children above six years of age [16,17].

Delamanid and bedaquiline have been proven to be effective in increasing sputum smear and culture conversion, and in improving success rates at the end of treatment, although concerns exist regarding the possible cardiotoxicity resulting from drug interactions with other drugs known to increase the QT interval (the measure of time between the start of the $Q$ wave and the end of the $\mathrm{T}$ wave in the heart's electrical cycle), such as fluoroquinolones and clofazimine [18-26].

Bedaquiline (previously known also as TMC207 or R207910) belongs to the diarylquinoline group, and it was developed by Janssen Pharmaceuticals (Titusville, NJ, USA) [27]. This is the first anti-TB drug discovered and developed in its class. Structurally, it presents a quinolinic central heterocyclic nucleus with alcohol and amine side chains that are the key effectors for its antimycobacterial activity. So far, bedaquiline acts by inhibiting the mycobacterial ATP synthase, thus being the first and only anti-TB drug targeting the energy metabolism of mycobacteria [18]). Bedaquiline is characterised by long half-life well exceeding $24 \mathrm{~h}$. Clinical studies have evidenced good early bactericidal activity, safety, tolerability, and pharmacokinetic profile of bedaquiline; this has led to early accelerated or conditional approval in the USA (2012) and Europe (2014) for use in MDR-TB [18].

Delamanid (previously known also as OPC-67683) is a nitro-dihydro-imidazooxazole derivative belonging to the class of nitroimidazoles. It was developed and produced by Otsuka Pharmaceutical Development and Commercialization (Osaka, Tokyo, Japan) [19]. The mycobacterial wall is well known to be wax-rich; one of the key components of mycobacterial wax is mycolic acid. The molecular mechanism of action of delamanid and its class is based on its capacity to inhibit the biosynthesis of mycolic acid. During its development delamanid showed a brilliant in-vitro and in-vivo activity, being efficacious against both extra- and intracellular mycobacteria. Clinical studies showed good tolerability in the absence of frequent severe adverse events with a non-clinically significant effect on the QTC interval [19]. Although there are other promising drugs in this class, such as PA-824, delamanid is the first drug in its class to reach approval and clinical use.

The difficult task for any clinician dealing with MDR-TB is to ensure the minimum number of drugs necessary to design an effective regimen $[2,7,10,13,28]$.

In this regard, as of today, some repurposed drugs can be used including, among others, linezolid [29-35] and the carbapenems [36-41].

However, when patients have drug resistance profiles "beyond XDR-TB" [3,4] or intolerance to second-line drugs so that four active drugs are not available, clinicians may be forced to combine delamanid and bedaquiline [41].

Considering the forecasted harms and potential benefits of this drug combination, a review of the available scientific evidence on this topic is of crucial importance. 
The aim of the present manuscript is to perform a systematic review on the combined use of delamanid and bedaquiline.

\section{Methods}

We conducted a search of peer-reviewed, scientific evidence to evaluate the efficacy/effectiveness, safety, and tolerability of regimens containing delamanid and bedaquiline in individuals with pulmonary/extrapulmonary TB which was culture- and drug susceptibility testing (DST)-confirmed as M/XDR-TB.

The database PubMed was used to identify any manuscript, without any time constraints up until 23 December 2016. Conference abstracts were excluded on the basis of their limited word count, the information provided was considered insufficient to assess the objectives described above. Letters or case series/reports including detailed clinical information were considered. Only papers written in English were analysed.

The keywords TB, delamanid, and bedaquiline were used to be as inclusive as possible.

The following search exclusion criteria were used:

1 Experimental studies on animals with TB;

2 Reviews and editorials on delamanid and bedaquiline;

$3 \mathrm{M} / \mathrm{XDR}-\mathrm{TB}$ diagnosis of treated patients not confirmed with conventional bacteriological criteria.

Two authors independently performed the search and evaluated the titles and abstracts of the records according to the selection criteria. Potentially interesting articles were critically assessed; when they fulfilled the enrolment criteria, the planned information (e.g., sputum smear and culture conversion, treatment outcomes, adverse events and their grading, demographics, epidemiological data, drug resistance patterns of the collected Mycobacterium tuberculosis isolates, drug regimen prescribed and its duration) was retrieved and collected using a pre-defined electronic template. The study was conducted following the guidelines of the 2009 PRISMA (Preferred Reporting Items for Systematic Reviews and Meta-Analysis) statement [42].

\section{Results}

A total of 75 records were obtained from the search (PRISMA flowchart, Figure 1); 72 were excluded for the following reasons: dealing with only one of the two drugs (three studies), being recommendations on the individual or combined use (one document), identifying need for their use (one study), focusing on drug resistance aspects (six studies) or being generic reviews/other studies (61 papers).

Three studies [43-45] satisfied our criteria for further analysis, all of them being research letters published in 2016, and reporting a total of two cases. One study [45] updated another one [44], both being from the same authors.

The two cases were both XDR-TB and extremely complicated, one born in Africa and one in Asia, and exposed to the combination of delamanid and bedaquiline in 2015 and 2016, respectively.

For both of them, a study follow-up of six months is reported, with the achievement of sputum smear and culture conversion over the study period.

Only one case experienced the QT interval prolongation, followed by temporary discontinuation of bedaquiline, and re-administration after the prescription of verapamil [43].

Although the QT interval transiently increased from week 5 to week 17, it then decreased below $500 \mathrm{~ms}$.

Details on the studies are reported in Tables 1-3. 

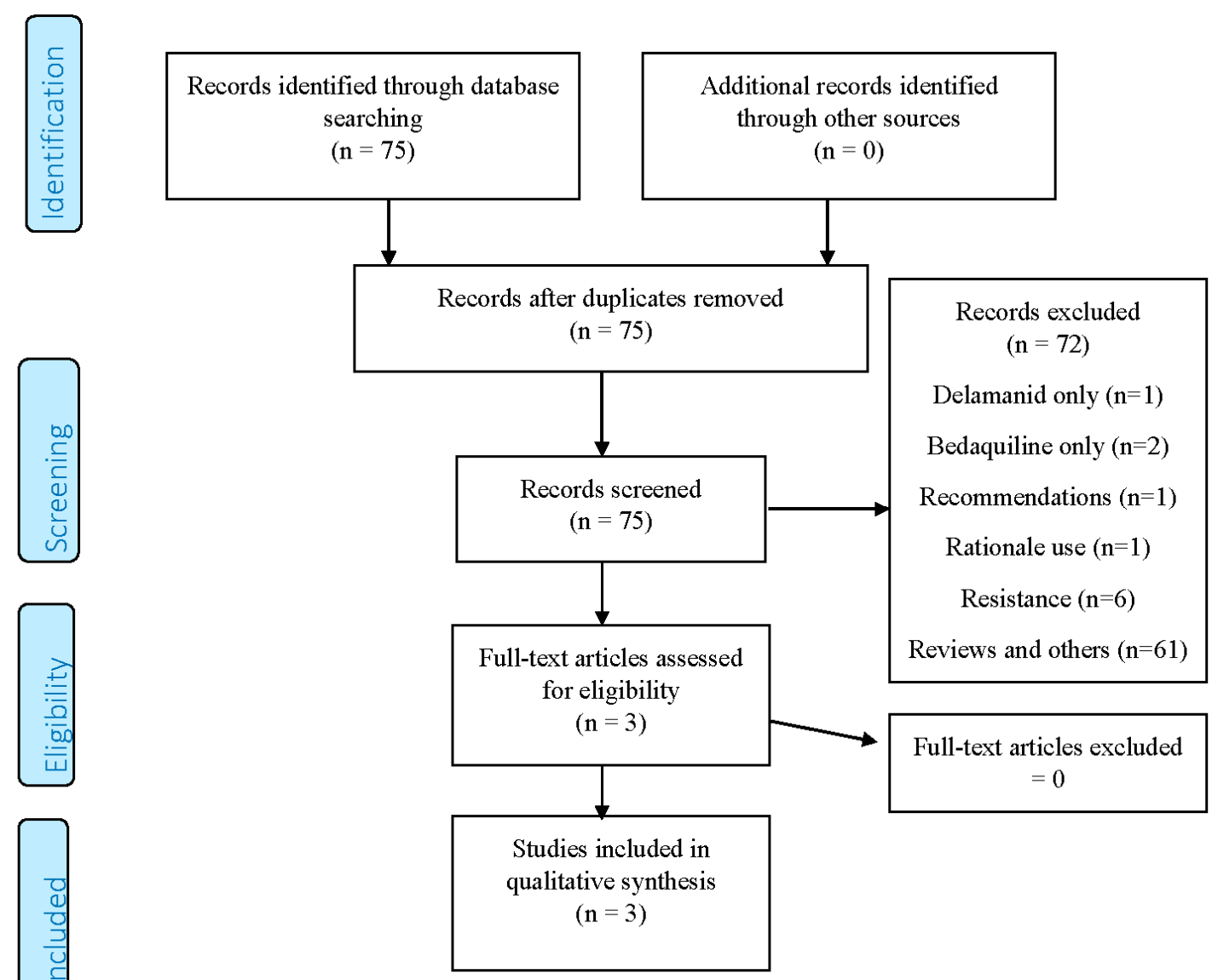

Figure 1. PRISMA (Preferred Reporting Items for Systematic Reviews and Meta-Analysis) 2009 Flow Diagram.

Table 1. Epidemiological characteristics of the selected studies.

\begin{tabular}{cccccc}
\hline First Author & $\begin{array}{c}\text { Publication } \\
\text { Year }\end{array}$ & Country & Study Design & Clinical Setting & Study Duration \\
\hline Lachâtre M. [43] & 2016 & France & Case 1 Report & $\begin{array}{c}\text { Reference Hospital, } \\
\text { Paris, France }\end{array}$ & March-September 2015 \\
\hline Tadolini M. [44] & 2016 & India & Case 2 Report & $\begin{array}{c}\text { Reference Hospital, } \\
\text { Dharamshala, India }\end{array}$ & February-March 2016 \\
\hline Tadolini M. [45] & 2016 & India & Case 2 Report update & $\begin{array}{r}\text { Reference Hospital, } \\
\text { Dharamshala, India }\end{array}$ & February-July 2016 \\
\hline
\end{tabular}


Table 2. Clinical features of the selected studies.

\begin{tabular}{|c|c|c|c|c|c|c|}
\hline First Author & $\begin{array}{l}\text { Number of Individuals } \\
\text { Exposed to Delamanid + } \\
\text { Bedaquiline/HIV Status }\end{array}$ & $\begin{array}{c}\text { Age (Years)/ } \\
\text { Sex/Country of Birth }\end{array}$ & $\begin{array}{c}\text { XDR-TB/ } \\
\text { Previous Relapses }\end{array}$ & $\begin{array}{l}\text { Body Weight at the } \\
\text { Start of Treatment }\end{array}$ & Drug Resistance Profile & $\begin{array}{l}\text { Regimen Administered } \\
\text { (Doses if Available) }\end{array}$ \\
\hline Lachâtre M. [43] & 1, HIV ND & 20/male/DR Congo & Yes/ND & ND & ND & $\begin{array}{l}\text { delamanid, bedaquiline, ethambutol, } \\
\text { para-aminosalicylic acid, linezolid, } \\
\text { imipenem, amoxicillin/clavulanate }\end{array}$ \\
\hline Tadolini M. [44] & 1, HIV negative & 39/female/Tibet & Yes/2 & $65 \mathrm{~kg}$ & $\begin{array}{l}\text { Resistant to } 12 \text { drugs: isoniazid, } \\
\text { rifampicin, kanamycin, amikacin, } \\
\text { capreomycin, moxifloxacin, ofloxacin, } \\
\text { ethionamide, Para-amino-salicylic acid, } \\
\text { linezolid, high dose isoniazid, } \\
\text { moxifloxacin, Susceptible to: clofazimine }\end{array}$ & $\begin{array}{l}\text { delamanid }(200 \mathrm{mg}) \text {, bedaquiline } \\
(400 \mathrm{mg}), \text { clofazimine }(200 \mathrm{mg}), \\
\text { terizidone }(1 \mathrm{~g}), \text { meropenem } 1 \mathrm{~g} \text { TID, } \\
\text { amoxicillin/clavulanate } 1 \mathrm{~g} / \\
200 \mathrm{mg} \text { TID i.v. })\end{array}$ \\
\hline Tadolini M. [45] & same as above & same as above & same as above & same as above & same as above & \\
\hline
\end{tabular}

TID: Thrice a day, i.v.: intravenously; ND: Not Declared; XDR-TB: extensively drug-resistant tuberculosis.

Table 3. Effectiveness, safety, and tolerability profiles of delamanid and bedaquiline combination in the selected studies.

\begin{tabular}{|c|c|c|c|c|c|}
\hline First Author & $\begin{array}{l}\text { Sputum Smear } \\
\text { Conversion }\end{array}$ & $\begin{array}{l}\text { Sputum Culture } \\
\text { Conversion }\end{array}$ & Treatment Outcome & QT Interval Prolongation & $\begin{array}{c}\text { Interruption of Bedaquiline or } \\
\text { Delamanid due to Adverse Events }\end{array}$ \\
\hline Lachâtre M. [43] & Yes & Yes & $\begin{array}{l}\text { After six months favourable } \\
\text { clinical, microbiological, and } \\
\text { radiological responses }\end{array}$ & No & ND \\
\hline Tadolini M. [44] & Yes & Yes & $\begin{array}{l}\text { After two months favourable } \\
\text { clinical, microbiological, and } \\
\text { radiological responses }\end{array}$ & Yes & $\begin{array}{l}\text { Bedaquiline stopped on 7th March } \\
2016 \text { restarted on } 12 \text { March } 2016\end{array}$ \\
\hline Tadolini M. [45] & $\begin{array}{l}\text { Yes (consistent negative } \\
\text { sputum smear) }\end{array}$ & $\begin{array}{l}\text { Yes (consistent } \\
\text { negative culture) }\end{array}$ & $\begin{array}{l}\text { After six months favourable } \\
\text { clinical, microbiological, and } \\
\text { radiological responses. Body } \\
\text { weight increased } 4 \mathrm{~kg} .\end{array}$ & $\begin{array}{l}\text { Yes, W5: } 508 \mathrm{~ms} ; \mathrm{W} 7: 500 \mathrm{~ms} ; \mathrm{W} 8: 508 \\
\text { ms; W12: } 512 \mathrm{~ms} ; \mathrm{W} 13: 510 \mathrm{~ms} ; \\
\text { W15: 507; W16: } 520 \mathrm{~ms} \text {; W17: } 501 \mathrm{~ms}\end{array}$ & $\begin{array}{l}\text { Not after } 12 \text { March } 2016 \text { and } \\
\text { addition of verapamil }\end{array}$ \\
\hline
\end{tabular}

ND: Not Declared; W: week; ms: milliseconds. 


\section{Discussion}

The aim of the present study was to systematically review the available scientific evidence on the combined use of delamanid and bedaquiline in M/XDR-TB patients.

Only three papers included information of cases (two) treated with a combination of the two new drugs.

The information is scarce due also to the preliminary format used (letter) which does not allow for the inclusion of detail. The main conclusions which can be drawn from this analysis are the following:

1. In extremely challenging $M / X D R-T B$ cases, when the number of drugs are not enough to reach the recommended number of at least four to design an effective regimen, some clinicians have considered using delamanid and bedaquiline in combination.

2. The combination was effective in the two cases observed as it achieved smear and culture conversion, but their number is insufficient to draw any firm conclusions.

3. The combination of delamanid and bedaquiline, and, eventually, of other QT interval-prolonging drugs (e.g., fluoroquinolones, clofazimine) is prone to adverse events and potentially harmful QT prolongation [41,46]. The recommendation to obtain and assess a baseline electrocardiogram (ECG) prior to starting the combination treatment and regularly repeat ECGs during treatment with such drugs to monitor the QT interval is not just 'formal', but clinically relevant. ECG should be performed at baseline and, then, at regular intervals (e.g., weekly on the first instance and in reduced frequency should QTc prolongation not manifest).

4. Electrolytes (potassium and magnesium) as well as albumin should be monitored as electrolyte disturbance and/or hypoalbuminemia (delamanid) may precede QTc prolongation.

5. Given the arguments above, only specialised centres should manage patients with delamanid-bedaquiline combined treatment, according to the criteria proposed by Matteelli A. et al. [41].

6. As the global experience with combined delamanid-bedaquiline treatment is still very limited, new clinical trials are needed to assess the real efficacy, safety, and tolerability of these drugs in TB cases with complicated drug-resistance patterns.

7. Interestingly, both patients made a good clinical improvement on treatment. Surgery was performed on the Congolese patient (who likely benefited from it). However, the Tibetan patient could not afford an operation having bilateral lesions at the chest radiography. The combination regimen may be surgery-sparing; it could be utilised in patients with relative or absolute contraindications for surgery. [43-45].

8. No published evidence is available in children yet, although clinically-based recommendations have been recently published in this sense [17] and a recent study by Medecins Sans Frontieres (MSF) demonstrates the real need to increase the availability of new drugs [47]. Interestingly, a preliminary report from the MSF projects presented in Liverpool on 24 cases [48] seems to be encouraging.

More experience with these two agents is, therefore, needed. Two clinical trials NCT02583048 (recruiting) and NCT02754765 (planned) [27] may shed more light on this combination and any possible major interactions. Preliminary data from the first aforementioned trial may be available by April 2017. Moreover, NCT02583048 is recruiting from only one of three sites and with an estimated enrollment of 84 patients. It is unlikely that we will have trial-based safety data anytime soon.

Another nitroimidazole, pretomanid, appears to work in synergy with bedaquiline [49], therefore excluding major class effects.

In conclusion, more evidence is needed on the combined use of delamanid and bedaquiline. 
Author Contributions: Giovanni Battista Migliori performed the literature review and wrote the first draft of the manuscript; Emanuele Pontali and Giovanni Sotgiu analysed critically the literature review; Rosella Centis and Lia D'Ambrosio participated in the literature review and in the preparation of the first draft of the manuscript; Simon Tiberi and Marina Tadolini gave a substantial scientific contribution on the text; Susanna Esposito proposed the topic and critically revised the paper. All the authors approved the final version of the manuscript.

Conflicts of Interest: The authors declare no conflict of interest.

\section{References}

1. World Health Organization. Global Tuberculosis Report 2016; WHO/HTM/TB/2016.13; World Health Organization: Geneva, Switzerland, 2016. Available online: http://www.who.int/tb/publications/global_ report/en/ (accessed on 30 December 2016).

2. Tiberi, S.; D’Ambrosio, L.; de Lorenzo, S.; Viggiani, P.; Centis, R.; Migliori, G.B. Tuberculosis elimination, patients' lives and rational use of new drugs: Revisited. Eur. Respir. J. 2016. [CrossRef] [PubMed]

3. Falzon, D.; Gandhi, N.; Migliori, G.B.; Sotgiu, G.; Cox, H.S.; Holtz, T.H.; Hollm-Delgado, M.G.; Keshavjee, S.; de Riemer, K.; Centis, R.; et al. Collaborative Group for Meta-Analysis of Individual Patient Data in MDR-TB. Resistance to fluoroquinolones and second-line injectable drugs: Impact on multidrug-resistant TB outcomes. Eur. Respir. J. 2013, 42, 156-168. [CrossRef] [PubMed]

4. Migliori, G.B.; Sotgiu, G.; Gandhi, N.R.; Falzon, D.; de Riemer, K.; Centis, R.; Hollm-Delgado, M.G.; Palmero, D.; Pérez-Guzmán, C.; Vargas, M.H.; et al. Collaborative Group for Meta-Analysis of Individual Patient Data in MDR-TB. Drug resistance beyond extensively drug-resistant tuberculosis: Individual patient data meta-analysis. Eur. Respir. J. 2013, 42, 169-179. [CrossRef] [PubMed]

5. Diel, R.; Rutz, S.; Castell, S.; Schaberg, T. Tuberculosis: Cost of illness in Germany. Eur. Respir. J. 2012, 40, 143-151. [CrossRef] [PubMed]

6. Diel, R.; Vandeputte, J.; de Vries, G.; Stillo, J.; Wanlin, M.; Nienhaus, A. Costs of tuberculosis disease in the European Union: A systematic analysis and cost calculation. Eur. Respir. J. 2014, 43, 554-565. [CrossRef] [PubMed]

7. World Health Organization. WHO Treatment Guidelines for Drug-Resistant Tuberculosis 2016 Update; WHO/HTM/TB 2016.04; World Health Organization: Geneva, Switzerland, 2016. Available online: http: / /apps.who.int/iris/bitstream/10665/250125/1/9789241549639-eng.pdf (accessed on 30 December 2016).

8. Migliori, G.B.; de Iaco, G.; Besozzi, G.; Centis, R.; Cirillo, D.M. First tuberculosis cases in Italy resistant to all tested drugs. Euro Surveill. 2007, 12, E070517.1. [PubMed]

9. Caminero, J.A.; Scardigli, A. Classification of antituberculosis drugs: A new proposal based on the most recent evidence. Eur. Respir. J. 2015, 46, 887-893. [CrossRef] [PubMed]

10. Sotgiu, G.; Tiberi, S.; D’Ambrosio, L.; Centis, R.; Alffenaar, J.W.; Caminero, J.A.; Arbex, M.A.; Guizado, V.A.; Aleksa, A.; Dore, S.; et al. Faster for less, the new "Shorter" regimen for multidrug-resistant tuberculosis. Eur. Respir. J. 2016, 48, 1503-1507. [CrossRef] [PubMed]

11. Falzon, D.; Jaramillo, E.; Schünemann, H.J.; Arentz, M.; Bauer, M.; Bayona, J.; Blanc, L.; Caminero, J.A.; Daley, C.L.; Duncombe, C.; et al. WHO guidelines for the programmatic management of drug-resistant tuberculosis: 2011 update. Eur. Respir. J. 2011, 38, 516-528. [CrossRef] [PubMed]

12. Tiberi, S.; Scardigli, A.; Centis, R.; D’Ambrosio, L.; Muñoz-Torrico, M.; Salazar-Lezama, M.Á.; Spanevello, A.; Visca, D.; Zumla, A.; Migliori, G.B.; Luna, J.A. Classifying new anti-TB drugs: Rationale and future perspectives. Int. J. Infect. Dis. 2016. [CrossRef] [PubMed]

13. Sotgiu, G.; Pontali, E.; Centis, R.; D'Ambrosio, L.; Migliori, G.B. New anti-tuberculosis drugs for special populations: A difficult-to-address issue. Eur. Respir. J. 2016. [CrossRef] [PubMed]

14. World Health Organization. The Use of Delamanid in the Treatment of Multidrug-Resistant Tuberculosis: Interim Policy Guidance; WHO/HTM/TB2014.23; World Health Organization: Geneva, Switzerland, 2014. Available online: http://apps.who.int/iris/bitstream/10665/137334/1/WHO_HTM_TB_2014.23_eng.pdf (accessed on 30 December 2016).

15. World Health Organization. The Use of Bedaquiline in the Treatment of Multidrug-Resistant Tuberculosis: Interim Policy Guidance; WHO/HTM/TB/2013.6; World Health Organization: Geneva, Switzerland, 2013. Available online: http://apps.who.int/iris/bitstream/10665/84879/1/9789241505482_eng.pdf (accessed on 30 December 2016). 
16. World Health Organization. The Use of Delamanid in the Treatment of Multidrug-Resistant Tuberculosis in Children and Adolescents: Interim Policy Guidance; WHO/HTM/TB/2016.14; World Health Organization: Geneva, Switzerland, 2016. Available online: https://www.ghdonline.org/uploads/Delamanid_guideline_childadol_Oct16.pdf (accessed on 30 December 2016).

17. Harausz, E.P.; Garcia-Prats, A.; Seddon, J.A.; Schaaf, H.S.; Hesseling, A.; Achar, J.; Bernheimer, J.; Cruz, A.; D’Ambrosio, L.; Detjen, A.; et al. New Drugs, Repurposed Drugs, and Novel Regimens for Children with Multidrug-Resistant Tuberculosis: Practice-Based Recommendations. Am. J. Respir. Crit. Care Med. 2016. Available online: http:/ /www.atsjournals.org/doi/abs/10.1164/rccm.201606-1227CI?url_ver=Z39.88-2003\& rfr_id=ori\%3Arid\%3Acrossref.org\&rfr_dat=cr_pub\%3Dpubmed\& (accessed on 30 December 2016).

18. Pontali, E.; Sotgiu, G.; D'Ambrosio, L.; Centis, R.; Migliori, G.B. Bedaquiline and MDR-TB: A systematic and critical analysis of the evidence. Eur. Respir. J. 2016. [CrossRef] [PubMed]

19. Sotgiu, G.; Pontali, E.; Centis, R.; D'Ambrosio, L.; Migliori, G.B. Delamanid (OPC-67683) for treatment of multi-drug-resistant tuberculosis. Expert Rev. Anti Infect. Ther. 2015, 13, 305-315. [CrossRef] [PubMed]

20. Tadolini, M.; Garcia-Prats, A.J.; D'Ambrosio, L.; Hewison, C.; Centis, R.; Schaaf, H.S.; Marais, B.J.; Ferreira, H.; Caminero, J.A.; Jonckheere, S.; et al. Compassionate use of new drugs in children and adolescents with multidrug-resistant and extensively-drug resistant tuberculosis: Early experiences and challenges. Eur. Respir. J. 2016, 48, 938-943. [CrossRef] [PubMed]

21. Esposito, S.; D’Ambrosio, L.; Tadolini, M.; Schaaf, H.S.; Caminero Luna, J.; Marais, B.; Centis, R.; Dara, M.; Matteelli, A.; Blasi, F.; et al. ERS/WHO Tuberculosis Consilium assistance with extensively drug-resistant tuberculosis management in a child: Case study of compassionate delamanid use. Eur. Respir. J. 2014, 44, 811-815. [CrossRef] [PubMed]

22. Skripconoka, V.; Danilovits, M.; Pehme, L.; Tomson, T.; Skenders, G.; Kummik, T.; Cirule, A.; Leimane, V.; Kurve, A.; Levina, K.; et al. Delamanid improves outcomes and reduces mortality in multidrug-resistant tuberculosis. Eur. Respir. J. 2013, 41, 1393-1400. [CrossRef] [PubMed]

23. Gler, M.T.; Skripconoka, V.; Sanchez-Garavito, E.; Xiao, H.; Cabrera-Rivero, J.L.; Vargas-Vasquez, D.E.; Gao, M.; Awad, M.; Park, S.K.; Shim, T.S.; et al. Delamanid for multidrug-resistant pulmonary tuberculosis. N. Engl. J. Med. 2012, 366, 2151-2160. [CrossRef] [PubMed]

24. Pym, A.S.; Diacon, A.H.; Tang, S.J.; Conradie, F.; Danilovits, M.; Chuchottaworn, C.; Vasilyeva, I.; Andries, K.; Bakare, N.; de Marez, T.; et al. Bedaquiline in the treatment of multi- and extensively drug-resistant tuberculosis. Eur. Respir. J. 2016. [CrossRef] [PubMed]

25. Diacon, A.H.; Pym, A.; Grobusch, M.; Patientia, R.; Rustomjee, R.; Liesl, P.S.; Pistorius, C.; Krause, R.; Bogoshi, M.; Churchyard, G.; et al. The diarylquinoline TMC207 for multidrug-resistant tuberculosis. N. Engl. J. Med. 2009, 360, 2397-2405. [CrossRef] [PubMed]

26. Diacon, A.H.; Pym, A.; Grobusch, M.P.; de Ios Rios, J.M.; Gotuzzo, E.; Vasilyeva, I.; Leimane, V.; Andries, K.; Bakare, N.; de Marez, T.; et al. Multidrug-resistant tuberculosis and culture conversion with bedaquiline. N. Engl. J. Med. 2014, 371, 723-732. [CrossRef] [PubMed]

27. ClinicalTrials.gov. A Service of the U.S. National Institutes of Health. Available online: www.clinicaltrials.gov (accessed on 12 January 2017).

28. Lienhardt, C.; Nahid, P.; Rich, M.L.; Bansbach, C.; Kendall, E.A.; Churchyard, G.; González-Angulo, L.; D'Ambrosio, L.; Migliori, G.B.; Raviglione, M. Target regimen profiles for treatment of tuberculosis: A WHO document. Eur. Respir. J. 2017. [CrossRef] [PubMed]

29. Sotgiu, G.; Pontali, E.; Migliori, G.B. Linezolid to treat MDR-/XDR-Tuberculosis: Available evidence and future scenarios. Eur. Respir. J. 2015, 45, 25-29. [CrossRef] [PubMed]

30. Villar, M.; Sotgiu, G.; D'Ambrosio, L.; Raymundo, E.; Fernandes, L.; Barbedo, J.; Diogo, N.; Lange, C.; Centis, R.; Migliori, G.B. Linezolid safety, tolerability and efficacy to treat multidrug- and extensively drug-resistant tuberculosis. Eur. Respir. J. 2011, 38, 730-733. [CrossRef] [PubMed]

31. De Lorenzo, S.; Centis, R.; D’Ambrosio, L.; Sotgiu, G.; Migliori, G.B. On linezolid efficacy and tolerability. Eur. Respir. J. 2012, 39, 770-772. [CrossRef] [PubMed] 
32. Sotgiu, G.; Centis, R.; D'Ambrosio, L.; Alffenaar, J.; Anger, H.; Caminero, J.; Castiglia, P.; de Lorenzo, S.; Ferrara, G.; Koh, W.; et al. Efficacy, safety and tolerability of linezolid containing regimens in treating MDR-TB and XDR-TB: Systematic review and meta-analysis. Eur. Respir. J. 2012, 40, 1430-1442. [CrossRef] [PubMed]

33. Sotgiu, G.; Centis, R.; D'Ambrosio, L.; Spanevello, A.; Migliori, G.B. International Group for the study of Linezolid. Linezolid to treat extensively drug-resistant TB: Retrospective data are confirmed by experimental evidence. Eur. Respir. J. 2013, 42, 288-290. [CrossRef] [PubMed]

34. Lee, M.; Lee, J.; Carroll, M.W.; Choi, H.; Min, S.; Song, T.; Via, L.E.; Goldfeder, L.C.; Kang, E.; Jin, B.; et al. Linezolid for treatment of chronic extensively drug-resistant tuberculosis. N. Engl. J. Med. 2012, 367, 1508-1518. [CrossRef] [PubMed]

35. Sotgiu, G.; Centis, R.; D'Ambrosio, L.; Castiglia, P.; Migliori, G.B. Low minimal inhibitory concentrations of linezolid against multidrug-resistant tuberculosis strains. Eur. Respir. J. 2015, 45, 287-289. [CrossRef] [PubMed]

36. De Lorenzo, S.; Alffenaar, J.W.; Sotgiu, G.; Centis, R.; D'Ambrosio, L.; Tiberi, S.; Bolhuis, M.S.; van Altena, R.; Viggiani, P.; Piana, A.; et al. Efficacy and safety of meropenem-clavulanate added to linezolid-containing regimens in the treatment of MDR-/XDR-TB. Eur. Respir. J. 2013, 41, 1386-1392. [CrossRef] [PubMed]

37. Tiberi, S.; Payen, M.C.; Sotgiu, G.; D’Ambrosio, L.; Alarcon Guizado, V.; Alffenaar, J.W.; Abdo Arbex, M.; Caminero, J.A.; Centis, R.; de Lorenzo, S.; et al. Effectiveness and safety of meropenem/ clavulanate-containing regimens in the treatment of multidrug and extensively drug-resistant tuberculosis. Eur. Respir. J. 2016, 47, 1235-1243. [CrossRef] [PubMed]

38. Tiberi, S.; Sotgiu, G.; D'Ambrosio, L.; Centis, R.; Abdo Arbex, M.; Alarcon Arrascue, E.; Alffenaar, J.W.; Caminero, J.A.; Gaga, M.; Gualano, G.; et al. Effectiveness and Safety of Imipenem-Clavulanate Added to an Optimized Background Regimen (OBR) versus OBR Control Regimens in the Treatment of Multidrug-Resistant and Extensively Drug-Resistant Tuberculosis. Clin. Infect. Dis. 2016. [CrossRef] [PubMed]

39. Tiberi, S.; Sotgiu, G.; D'Ambrosio, L.; Centis, R.; Abdo Arbex, M.; Alarcon Arrascue, E.; Alffenaar, J.W.; Caminero, J.A.; Gaga, M.; Gualano, G.; et al. Comparison of effectiveness and safety of imipenem/ clavulanate- versus meropenem/clavulanate-containing regimens in the treatment of multidrug and extensively drug-resistant tuberculosis. Eur. Respir. J. 2016. [CrossRef]

40. Tiberi, S.; D'Ambrosio, L.; de Lorenzo, S.; Viggiani, P.; Centis, R.; Sotgiu, G.; Alffenaar, J.W. Migliori, G.B. Ertapenem in the treatment of multidrug-resistant tuberculosis: First clinical experience. Eur. Respir. J. 2016, 47, 333-336. [CrossRef] [PubMed]

41. Matteelli, A.; D'Ambrosio, L.; Centis, R.; Tadolini, M.; Migliori, G.B. Compassionate and optimum use of new tuberculosis drugs. Lancet. Infect. Dis. 2015, 15, 1131-1132. [CrossRef]

42. Moher, D.; Liberati, A.; Tetzlaff, J.; Altman, D.G.; The Prisma Group. Preferred Reporting Items for Systematic Reviews and Meta-Analyses: The PRISMA Statement. PLoS Med. 2009, 6, e1000097. [CrossRef] [PubMed]

43. Lachâtre, M.; Rioux, C.; Le Dû, D.; Frèchet-Jachym, M.; Veziris, N.; Bouvet, E.; Yazdanpanah, Y. Bedaquiline plus delamanid for XDR tuberculosis. Lancet. Infect. Dis. 2016, 16, 294. [CrossRef]

44. Tadolini, M.; Lingtsang, R.D.; Tiberi, S.; Enwerem, M.; D’Ambrosio, L.; Sadutshang, T.D.; Centis R Migliori, G.B. First case of extensively drug-resistant tuberculosis treated with both delamanid and bedaquiline. Eur. Respir. J. 2016, 48, 935-938. [CrossRef] [PubMed]

45. Tadolini, M.; Lingtsang, R.D.; Tiberi, S.; Enwerem, M.; D’Ambrosio, L.; Sadutshang, T.D.; Centis, R.; Migliori, G.B. Cardiac safety of extensively drug-resistant tuberculosis regimens including bedaquiline, delamanid, and clofazimine. Eur. Respir. J. 2016. [CrossRef] [PubMed]

46. Wallis, R.S. Cardiac safety of extensively drug-resistant tuberculosis regimens including bedaquiline, delamanid and clofazimine. Eur. Respir. J. 2016. [CrossRef] [PubMed]

47. Bonnet, M.; Bastard, M.; du Cros, P.; Khamraev, A.; Kimenye, K.; Khurkhumal, S.; Hayrapetyan, A.; Themba, D.; Telnov, A.; Sanchez-Padilla, E.; Hewison, C.; Varaine, F. Identification of patients who could benefit from bedaquiline or delamanid: A multisite MDR-TB cohort study. Int. J. Tuberc. Lung Dis. 2016, 20, 177-186. [CrossRef] [PubMed] 
48. Ferlazzo, G. Dlm-Bdq combination: Programmatic aspects and preliminary results of patients receiving Dlm and Bdq combination in MSFNTP projects. Satellite session (SS) 02. Pushing the boundaries: Use of new TB drugs. In Proceedings of the 47th Union World Conference on Lung Health, Liverpool, UK, 26-29 October 2016.

49. Conradie, F.; Diacon, A.; Mendel, C.; Everitt, D.; van Niekerk, C.; Howell, P.; Spigelman, M. Interim results of nix-TB clinical study of pretomanid, bedaquiline and linezolid for treatment of XDR and treatment intolerant/failed MDR-TB. In Proceedings of the 47th Union World Conference on Lung Health, Liverpool, UK, 26-29 October 2016.

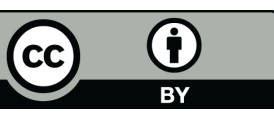

(C) 2017 by the authors; licensee MDPI, Basel, Switzerland. This article is an open access article distributed under the terms and conditions of the Creative Commons Attribution (CC BY) license (http://creativecommons.org/licenses/by/4.0/). 